\title{
Makarna ve Erişte Türlerindeki Tiaminin İn Vitro Olarak Biyoerişilebilirliğinin Saptanması
}

\author{
Serap Andaç-Öztürk ${ }^{1 *}$, \\ 1* İstanbul Sabahatin Zaim Üniversitesi, Sağlık Bilimleri Fakültesi, Beslenme ve Diyetetik Bölümü, İstanbul, Türkiye, (ORCID: 0000-0002-6253-4118), \\ serap.ozturk@izu.edu.tr
}

(İlk Geliş Tarihi 10 Kasım 2021 ve Kabul Tarihi 5 Ocak 2022)

(DOI: 10.31590 /ejosat.)

ATIF/REFERENCE: Andaç-Öztürk, S. (2022). Makarna ve Erişte Türlerindeki Tiaminin İn Vitro Olarak Biyoerişilebilirliğinin Saptanmas1. Avrupa Bilim ve Teknoloji Dergisi, (33), 74-78.

Öz

Makarna üretimi ucuz, hazırlaması kolay bir besin olup tüm dünyada en sevilen tahıl ürünlerinden bir tanesidir. Tahıllar genel olarak tiamin açısından da zengin besinlerdir. Bununla birlikte hazırlama, pişirme yöntemleri ya da ürün içeriği gibi faktörlerden dolayı besin ögeleri kayıpları olmakta ve besin ögelerinin biyoerişilebilirliği değişmektedir. Bu çalışmanın amacı farklı makarna ve erişte örneklerindeki tiamin miktarı ve biyoerişilebilirliğinin in vitro sindirim modeli ile incelenmesidir. Çalışmada vitamin içerikleri yüksek

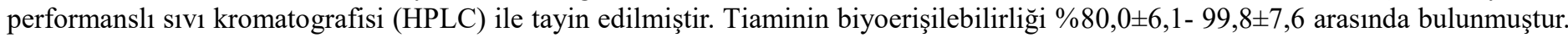
En düşük tiamin biyoerişilebilirliğinin yumurtalı eriştede olduğu saptanmıştır. En yüksek biyoerişilebilirliğin ise ıspanaklı makarnada olduğu gözlemlenmiştir. Sevilen bir besin olan makarnanın tiamin içeriklerinin göreceli düşük olduğu ve bireylerin beslenmelerinde tiamin içeriği yüksek olan tam tahıl ürünlerine yer vermeye özen göstermeleri gerektiği düşünülmüştür.

Anahtar Kelimeler: Makarna, Tiamin, Biyoerişilebilirlik.

\section{Determination of In Vitro Bioaccessibility of Thiamine in Pasta and Noodle Types}

\begin{abstract}
Pasta is cheap to produce, easy to prepare and one of the most popular grain products all over the world. Cereals are generally rich in thiamine. However, due to the factors such as preparation, cooking methods or product content, nutrient losses occure and the bioaccessibility of nutrients changes. The aim of this study is to investigate the amount and bioaccessibility of thiamine in different pasta and noodle samples by in vitro digestion model. In the study, vitamin contents were determined by high performance liquid chromatography (HPLC). The bioavailability of thiamine ranged from $80,0 \pm 6,1$ to 99,8 $7,6 \%$. The lowest thiamine bioaccessibility was found in noodles made with egg. The highest bioaccessibility was observed in spinach pasta. It was thought that the thiamine content of pasta, which is a popular food, is relatively low and it was considered that whole grain products with high thiamine content should be taken into the diet of individuals.
\end{abstract}

Keywords: Pasta, Thiamine, Bioaccessibility.

\footnotetext{
*Sorumlu Yazar: serap.ozturk@izu.edu.tr
} 


\section{Giriş}

Makarna Akdeniz diyetindeki temel besinlerdir biridir. Besin piramidinin temelini oluşturmaktadır ve günlük olarak tüketimi önerilmektedir (Melini, Melini ve Acquistucci, 2020). Üretiminin ucuz, hazırlamasının kolay olması bu ürünü tüm dünyadaki en popüler yüksek karbonhidratlı besinlerden bir tanesi haline getirmektedir. Makarna; \%74-77 oranında karbonhidrat, \%11-15 oranında ise protein içermektedir (Duda, Adamczak, Chelminska, Juszkiewicz ve Kowalczewski, 2019).

Yarı hazır bir gıda olan makarna, Triticum Durum buğdayının uygun şartlarda öğütülmesi ile elde edilen irmiğin, su, tuz ve diğer besleyici bileşenlerin katılması ve arzu edilen şekiller verilip kurutulmasıyla oluşturulan bir gıda ürünüdür. Ayrıca durum buğdayından elde edilen makarna $\mathrm{A}$ ve $\mathrm{B}$ grubu vitaminleri açısından da zengin bir besin kaynağıdır (Muslu, Gider, Dereli ve Yüksel, 2021).

Vitaminler besinlerin minör ancak elzem bileşenleridir. Suda çözünen vitamin grupları, yapısal, moleküler ağırlık, kimyasal ve biyolojik aktivitelerine göre değişik bileşikleri içerirler; tiamin, riboflavin, niasin, folik asit, pantotenik asit, vitamin $\mathrm{B}_{6}$, siyalokobalamin, biyotin gibi (Leporati vd., 2005). B grubu vitaminler fonksiyonları bakımından katabolizmadaki rolleri (enerji üretimi gibi) ve anabolizmadaki rolleri (biyoaktif moleküllerin transformasyonu ve yapımı gibi) olarak ikiye ayrılabilirler (Kennedy, 2016). Suda çözünen vitaminler vücutta depo edilmezler bu nedenle günlük olarak diyetle alınmaları gerekmektedir. Tahılların genel olarak saflaştırılmamış ve rafine edilmemiş formları, bu vitaminler için yaygın bir kaynaktır. Bununla birlikte rafine ve parlatma işlemleri tahıllarda önemli miktarda B vitamini kaybına neden olur (Schellack, Harirari ve Schellack, 2016). Tam tahıl ürünleri, kepekli pirinç, makarna ve yumurta, tiamin için iyi diyet kaynakları olarak gösterilmektedir (Kennedy, 2016).

Günlük vitamin alımları hesaplanırken gastrointestinal sistemdeki biyoerişilebilirlik belli olmadığı için biyoyararlanım da tam olarak tahmin edilememektedir (Yaman vd., 2021). Biyoerişilebilirlik gastrointestinal sistem boyunca besin matriksinden salınan bir bileşiğin emilim için mevcut olan miktarı olarak tanımlanmaktadır (López-Gámez, Elez-Martínez, MartínBelloso ve Soliva-Fortuny, 2021). Dolayısı ile biyoerişilebilirlik biyoaktif bileşenin besin matriksindeki içeriğinden daha önemlidir (López-Gámez vd., 2021). Ín vivo modellere alternatif olarak besin ögelerinin biyoerişilebilirliklerini saptamak adına in vitro yöntemler geliştirilmiş ve sıkça kullanılmaktadır (Yaman vd., 2021).

Biyoaktif bileşenlerin biyoerişilebilirliği içeriklerine, kimyasal yapılarına, matriks özelliklerine ve sindirim sırasındaki diğer bileşiklerle olan etkileşimlerine bağlı olarak değişmektedir. Besinin işlenmesi ya da adjuvantların eklenmesi bu özellikleri değiştirebilir ve biyoerişilebilirliği etkileyebilir (López-Gámez vd., 2021). Tüm bu bilgiler 1şığında bu çalışmanın amacı; toplumuz tarafindan sik tüketilen besinlerden olan makarna ve eriştelerin içerisinde bulunan tiamininin in vitro biyoerişilebilirliğinin incelenmesidir.

\section{Materyal ve Metot}

\section{1. Örneklem}

Çalışma örneklemini İstanbul ilindeki marketlerde satılmakta olan değişik markalara ait, çeşitli ürün içeriklerine sahip toplam 10 makarna, 4 erişte oluşturmaktadır. Ürün içerikleri Tablo 1' de sunulmuştur.

\subsection{Tiamin Ekstraksiyonu}

Ürünlerdeki tiaminin ekstraksiyonu için Ndaw ve arkadaşları tarafindan belirlenmiş olan yöntem kısmi değişiklikler uygulanarak kullanılmıştır (Ndaw, Bergaentzlé, Aoudé-Werner ve Hasselmann, 2000). Üretici firmanın talimatları doğrultusunda hazırlanan ürünler homojenize edildikten sonra 5 g'lık örnekler tartılarak $100 \mathrm{ml}$ 'lik erlenlere konuldu. Mevcut örneklere $50 \mathrm{ml}$ $0,1 \mathrm{~N}$ hidroklorik asit çözeltisi ilave edilerek, $121^{\circ} \mathrm{C}$ 'de 30 dakika otoklavlandı. Örnekler oda sicaklığına kadar soğutuldu ve 2,5 M'lik sodyum asetat çözeltisi ile $\mathrm{pH} 4,5$ 'e getirildi. Fosfat ve glikozit bağlı olan vitaminlerin enzimatik olarak serbest hale getirilebilmesi için; $100 \mathrm{mg}$ taka-diastaz, $5 \mathrm{mg}$ asit fosfataz ve 10 mg $\beta$-glukozidaz enzimleri ilave edildi ve çalkalamalı su banyosunda $45^{\circ} \mathrm{C}$ 'de 3 saat inkübe edildi. $\mathrm{Bu}$ işlemden sonra hacim 0,1 N hidroklorik asit çözeltisi ile $100 \mathrm{ml}$ 'ye tamamland. Karışım sırasıyla adi filtre kâğıdından ve $0,45 \mu \mathrm{m}$ 'luk selüloz asetat filtreden geçirilerek HPLC'ye enjekte edildi.

\subsection{HPLC ile Tiamin Analizi}

Tiaminin floresans dedektörde tespit edilebilmesi için potasyum ferrisiyanid çözeltisi ile floresans dedektörde tespit edilebilir formu olan tiokroma dönüştürüldü. Bunun için \%1'lik ferrisiyanid çözeltisi \%15'lik sodyum hidroksit çözeltisi içinde hazırlandı. Ekstraksiyon aşamasında hazırlanan örnekten $20 \mathrm{ml}$ alındı ve üzerine $1,5 \mathrm{ml} \% 1$ 'lik ferrisiyanid çözeltisi ilave edildi. Elde edilen karışımın pH'1 ortofosforik asit çözeltisi pH 7,1'e ayarlandı. Aynı şekilde tiyamin standartları da \%1'lik ferrisiyanid çözeltisi ile türevlendirildi ve pH'1 7,1'e orta fosforik asit çözeltisi ile ayarland. Analizler Shimadzu Nexera-i (Shimadzu Corporation, Kyoto, Japan) marka HPLC cihazı ve floresans dedektör ile gerçekleştirildi. Floresans dedektör eksitasyon 366 nm'ye, emisyon ise 445 nm'ye ayarland. Tiokrom formuna dönüştürülen vitamin $\mathrm{B}_{1}{ }^{\prime} \mathrm{i}$ ayırma işleminde Gemini-NX $5 \mu \mathrm{C} 18$ $110 \AA$ A, 4.6 x 250 mm (Phenomenex, CA, USA) kolon kullanıldı. Akış hızı $1 \mathrm{ml} /$ dakika'ya kolon sıcaklığı ise $25^{\circ} \mathrm{C}$ 'ye ayarlandı. HPLC'de gerçekleştirilen bu ayırma işlemi 20 dakikada tamamland1.

\subsection{In vitro Biyoerişilebilirlik}

Makarna ve eriştelerdeki tiaminin biyoerişilebirliği in vitro gastrointestinal sistemin simülasyonu ile gerçekleştirilmiştir ve bu analiz prosedüründe Lee ve arkadaşları tarafından önerilen yöntem kullanılmıştır (Lee, Lee, Chung ve Hur, 2016). Bu kapsamda ağız, mide ve ince bağırsak solüsyonları hazırlanmıştır.

\subsubsection{A}

Sırası ile sodyum klorür $(175,3 \mathrm{~g} / \mathrm{L})$ ve üre $(25 \mathrm{~g} / \mathrm{L})$, çözeltileri hazırlandı. $500 \mathrm{ml}$ 'lik erlen içerisine $1,7 \mathrm{ml}$ sodyum klorür çözeltisi, $8 \mathrm{ml}$ üre çözeltisi ve $400 \mathrm{ml}$ deiyonize su ilave edilmiştir. Mevcut karıșıma $15 \mathrm{~g}$ ürik asit, $280 \mathrm{mg} \alpha$-amilaz ve 25 mg müsin ilave edilerek hacim $500 \mathrm{ml}$ 'ye tamamlanmıştır. Çözelti $1 \mathrm{M} \mathrm{HCI}$ ya da $1 \mathrm{M} \mathrm{NaOH}$ kullanılarak pH'1 6,8-7,0 olacak şekilde ayarlanmıştır. 


\subsubsection{Mide Solüsyonu:}

Sıra ile $\mathrm{HCI}(37 \mathrm{~g} / \mathrm{L})$ ve $\mathrm{CaCl}_{2} \cdot \mathrm{H}_{2} \mathrm{O}(22 \mathrm{~g} / \mathrm{L})$ çözeltileri hazırlandı. $\mathrm{HCI}$ çözeltisinden $6,5 \mathrm{ml}, \mathrm{CaCl}_{2} \cdot \mathrm{H}_{2} \mathrm{O}$ çözeltisinden $18 \mathrm{ml}$ alınarak total hacim $500 \mathrm{ml}$ olacak şekilde deiyonize su ilave edildi. Mevcut çözeltiye $1 \mathrm{~g}$ sı̆̆ır serum albumin, 2,5 g pepsin ve $3 \mathrm{~g}$ musin ilave edilerek çözündürüldü. Çözelti $1 \mathrm{M} \mathrm{HCI}$ ya da $1 \mathrm{M}$ $\mathrm{NaOH}$ kullanılarak pH'ı 1,5'e olacak şekilde ayarlandi.

\subsubsection{Ince Bağırsak Solüsyonu}

Sira ile $\mathrm{KCl}(89,6 \mathrm{~g} / \mathrm{L})$ ile $\mathrm{CaCl}_{2} \cdot 2 \mathrm{H}_{2} \mathrm{O}(22,2 \mathrm{~g} / \mathrm{L})$ çözeltileri hazırlandı. KCI çözeltisinden $6,3 \mathrm{ml}, \mathrm{CaCl}_{2} \cdot 2 \mathrm{H}_{2} \mathrm{O}$ çözeltisinden ise $9 \mathrm{ml}$ alınarak total hacim $500 \mathrm{ml}$ olacak şekilde deiyonize su ilave edildi. Daha sonra üzerine, $1 \mathrm{~g}$ sığır albümin, $1,5 \mathrm{~g}$ lipaz ve $1 \mathrm{~g}$ pankreatin ilave edilerek çözündürüldü. Çözelti $1 \mathrm{M}$ HCI ya da $1 \mathrm{M} \mathrm{NaOH}$ kullanılarak pH'1 8 olacak şekilde ayarlandı.

\subsubsection{Safra Solüsyonu:}

Sira ile $\mathrm{NaHCO}_{3}(84,7 \mathrm{~g} / \mathrm{L})$ ile $\mathrm{CaCl}_{2} \cdot 2 \mathrm{H}_{2} \mathrm{O}(22,2 \mathrm{~g} / \mathrm{L})$ çözeltileri hazırlandı. $500 \mathrm{ml}$ 'lik erlen içerisine $68,3 \mathrm{~mL} \mathrm{NaHCO}_{3}$ çözeltisi, $10 \mathrm{ml} \mathrm{CaCl} 2 \cdot 2 \mathrm{H}_{2} \mathrm{O}$ çözeltisi ve $400 \mathrm{ml}$ deiyonize su ilave edildi. Daha sonra $1,8 \mathrm{~g}$ sığır albümini ve $30 \mathrm{~g}$ safra ilave edilerek çözündürüldü, total hacim deiyonize su ile $500 \mathrm{ml}$ 'ye tamamlandı. Çözelti 1M HCI ya da $1 \mathrm{M} \mathrm{NaOH}$ kullanılarak pH'1 7,0 olacak şekilde ayarlandi.

\subsubsection{In vitro Sindirim}

$5 \mathrm{~g}$ homojen edilmiş makarna ve erişte çeşitleri $100 \mathrm{ml}$ beher içinde alındı ve üzerine ağız solüsyonundan $5 \mathrm{ml}$ ilave edildi. Ağız solüsyonu ile örneğin tam karışımının sağlanabilmesi için vorteks ile iyice karıştırıldı. Karışım çalkalamalı su banyosunda 5 dakika süre ile $37^{\circ} \mathrm{C}$ 'de inkübe edildi. İşlem bitiminde karışıma mide solüsyonundan $12 \mathrm{ml}$ eklenerek, vorteks ile iyice karıștırıldı. Karışım $37^{\circ} \mathrm{C}$ 'de 2 saat süre inkübe edildi. Daha sonra ince bağırsak ortamı için öncelikle $5 \mathrm{ml}$ safra sıvısı ilave edildi ve ortamın pH'1 7,0'a ayarlandı. Sonrasında ince bağırsak solüsyonundan $10 \mathrm{ml}$ ilave edilerek, $37{ }^{\circ} \mathrm{C}$ 'de 2 saat süre ile çalkalamalı su banyosunda inkübe edildi. İn vitro sindirim tamamlandıktan sonra ortamın $\mathrm{pH}^{\prime} 1 \quad 1 \quad \mathrm{M}$ HCI çözeltisi kullanılarak 4,5'e ayarlandı. Üzerine $5 \mathrm{ml} 0,1 \mathrm{M}$ 'lık sodyum asetat tamponundan ilave edilerek son hacim deiyonize su ile 50 ml'ye tamamlandı. Mevcut karışım $50 \mathrm{ml}$ 'lik falkon tüp içine alınarak 8000 rpm'de 5 dakika süre santrifüj edildi. Santifüj edilen sıvıdan $20 \mathrm{ml}$ alındı ve üzerine $10 \mathrm{mg}$ asit fosfataz ve $5 \mathrm{mg}$ beta-glikozidaz enzimlerinden ilave edildi ve 3 saat çalkalamalı su banyosunda inkübe edildi. Bu aşamadan sonra 2,3'de belirtilen analiz yöntemleri uygulanmıştır.

\section{5.Miktar Tayini ve Kalite Kontrol}

Miktar tayini HPLC kromatogramındaki örnek altında kalan alanın uygun standart konsantrasyonun alanına oranlaması ile hesaplandi.

\section{6. İstatiksek Analizler}

Her bir çalışma üç kez tekrar edildi ve standart sapması hesaplandı. Uygulamalar arasındaki önemli farklılıklar tek yönlü varyans analizi (ANOVA $p<0.05$, Tukey testi) kullanılarak istatistiksel olarak değerlendirildi.

Tablo 1. Makarna ve erişte örneklerinin genel özellikleri ve temel içerikleri (Table 1. General characteristics and basic contents of pasta and noodle samples)

\begin{tabular}{|c|c|c|}
\hline Örnek no & Ürün özelliği & İçindekiler \\
\hline 1 & Glutensiz makarna & Misir unu, su \\
\hline 2 & Tam buğday unu makarnası & Tam durum buğdayı irmiği, su \\
\hline 3 & Siyez makarnası & Siyez buğdayı unu, tuz, su \\
\hline 4 & Kepekli makarna & Durum buğdayı irmiği, durum buğdayı kepeği, su \\
\hline 5 & Organik & Organik durum buğdayı irmiği, su \\
\hline 6 & Yüksek proteinli makarna & Durum buğdayı irmiği, protein karışımı, su \\
\hline 7 & Proteinli makarna & Durum buğgayı irmiği, su \\
\hline 8 & Domatesli makarna & Durum buğdayı irmiği, domates salçası, su \\
\hline 9 & Ispanaklı makarna & Durum buğdayı irmiği, 1spanak tozu, su \\
\hline 10 & Standart makarna & Durum buğdayı irmiği, su \\
\hline 11 & Ispanaklı erişte & Buğday unu, süt, yumurta, 1spanak kurusu, tuz, su \\
\hline 12 & Domatesli erişte & Buğday unu, süt, yumurta, domates kurusu, tuz, su \\
\hline 13 & Tam buğdaylı erişte & Tam buğday unu, süt, yumurta, tuz, su \\
\hline 14 & Yumurtalı erişte & Durum buğday irmiği, yumurta sarısı toz, su \\
\hline
\end{tabular}




\begin{tabular}{cccc}
\hline Örnek No & $\begin{array}{c}\text { Başlangıç değeri } \\
(\boldsymbol{\mu g} / \mathbf{1 0 0} \mathbf{g})\end{array}$ & $\begin{array}{c}\text { Sindirim sonrası değer } \\
(\boldsymbol{\mu g} / \mathbf{1 0 0} \mathbf{g})\end{array}$ & Biyoerişilebilirlik (\%) \\
\hline $\mathbf{1}$ & $11,8 \pm 0,5^{\mathrm{a}}$ & $9,9 \pm 0,4^{\mathrm{b}}$ & $83,9 \pm 6,4$ \\
$\mathbf{2}$ & $105,2 \pm 5,0^{\mathrm{a}}$ & $101,1 \pm 4,4^{\mathrm{a}}$ & $96,2 \pm 2,8$ \\
$\mathbf{3}$ & $50,9 \pm 2,3^{\mathrm{a}}$ & $47,6 \pm 2,1^{\mathrm{a}}$ & $93,8 \pm 7,1$ \\
$\mathbf{4}$ & $69,5 \pm 2,7^{\mathrm{a}}$ & $68,5 \pm 3,1^{\mathrm{a}}$ & $98,6 \pm 1,3$ \\
$\mathbf{5}$ & $52,7 \pm 2,6^{\mathrm{a}}$ & $50,1 \pm 2,3^{\mathrm{b}}$ & $95,3 \pm 6,1$ \\
$\mathbf{6}$ & $67,7 \pm 5,8^{\mathrm{a}}$ & $66,1 \pm 3,1^{\mathrm{a}}$ & $97,8 \pm 3,9$ \\
$\mathbf{7}$ & $62,3 \pm 2,8^{\mathrm{a}}$ & $56,0 \pm 2,5^{\mathrm{b}}$ & $90,0 \pm 6,8$ \\
$\mathbf{8}$ & $43,8 \pm 2,0^{\mathrm{a}}$ & $37,3 \pm 1,7^{\mathrm{b}}$ & $85,4 \pm 6,5$ \\
$\mathbf{9}$ & $43,8 \pm 2,0^{\mathrm{a}}$ & $43,7 \pm 2,0^{\mathrm{a}}$ & $99,8 \pm 7,6$ \\
$\mathbf{1 0}$ & $28,7 \pm 1,3^{\mathrm{a}}$ & $24,5 \pm 1,1^{\mathrm{b}}$ & $85,6 \pm 6,5$ \\
$\mathbf{1 1}$ & $41,8 \pm 1,9^{\mathrm{a}}$ & $37,0 \pm 1,7^{\mathrm{b}}$ & $88,8 \pm 6,7$ \\
$\mathbf{1 2}$ & $25,3 \pm 1,1^{\mathrm{a}}$ & $22,7 \pm 1,0^{\mathrm{b}}$ & $89,8 \pm 6,8$ \\
$\mathbf{1 3}$ & $58,5 \pm 2,6^{\mathrm{a}}$ & $52,4 \pm 2,4^{\mathrm{b}}$ & $89,7 \pm 6,8$ \\
$\mathbf{1 4}$ & $56,5 \pm 2,5^{\mathrm{a}}$ & $45,1 \pm 2,0^{\mathrm{b}}$ & $80,0 \pm 6,1$ \\
\hline
\end{tabular}

Aynı satırlarda farklı harfler uygulamalar arasında istatistiksel farklılıklar olduğunu göstermektedir (ANOVA $p<0.05$, Tukey testi).

\section{Araștırma Sonuçları ve Tartışma}

\subsection{Makarna ve Eriște Örneklerindeki Tiamin Miktarı}

Araştırmamızda farklı makarna ve erişte çeşitlerinde saptanmış olan tiamin miktarları Tablo 2'de gösterilmiştir.

Buna göre tiamin içeriği en yüksek ve düşük olan ürünler sırasıyla tam buğday unu makarnası $(105,2 \pm 5,0 \mu \mathrm{g} / 100 \mathrm{~g})$ ve glutensiz makarnadır $(11,8 \pm 0,5 \mu \mathrm{g} / 100 \mathrm{~g})$. Ulusal gida kompozisyonu veri tabanı TURKOMP' a göre sade, yumurtasız, kuru makarnanın tiamin içeriği $0,227 \mathrm{mg} / 100 \mathrm{~g}$, glutensiz makarnanın tiamin içeriği ise $0,077 \mathrm{mg} / 100 \mathrm{~g}$ olarak belirtilmektedir (TURKOMP, 2021). Diğer taraftan TURKOMP'da erişte için herhangi bir veriye ulaşılamamıştır. Buna göre tüm örneklerdeki tiamin içeriği TURKOMP'a göre daha düşük bulunmuştur.

\section{1. İn Vitro Sindirim Sonuçları}

Makarna ve eriştelerdeki tiamin biyoerişilebilirlikleri Tablo 2'de sunulmuştur. Ürünlerdeki tiamin biyoerişilebilirliği $\% 80,0 \pm 6,1$ ile $\% 99,8 \pm 7,6$ arasında değişmektedir. Ürünlerin biyoerişilebilirlik oranları incelendiğinde en yüksek biyoerişilebilirlik oranı \%99,8 7,6 ile 1spanaklı makarnada, en düşük biyoerişilebilirlik oranı $\% 80,0 \pm 6,1$ ile yumurtalı eriştede gözlemlenmiştir. Bununla birlikte, ürünler sindirim sonrası değerleri açısından değerlendirildiğinde en yüksek miktar tam buğday unu makarnası (sindirim sonrası tiamin miktarı 101,1 $\pm 4,4$ $\mu \mathrm{g} / 100 \mathrm{~g}$ ), ve kepekli makarnada (sindirim sonrası tiamin miktarı $68,5 \pm 3,1 \mu \mathrm{g} / 100 \mathrm{~g}) \quad$ saptanmıştır. En düşük tiamin biyoerişilebilirliği ise yumurtalı eriştede $\% 80,0 \pm 6,1$ görülmüştür. Ancak sindirim sonrası değerler açısından incelendiğinde ise tiamin içeriği en düşük ürün glutensiz makarna olarak belirlenmiştir (sindirim sonrası tiamin miktarı 9,9 $\pm 0,4 \mu \mathrm{g} / 100 \mathrm{~g}$ ).

Mevcut çalışmada beslenmemizde önemli yere sahip olan makarna ve erişte çeşitlerindeki tiamin miktarları tayin edilmiş ve biyoerişilebilirlikleri in vitro ortamda incelenmiştir. Tiamin, diğer adı ile $B_{1}$ vitamini ya da aneurin, elzem bir besin ögesi olup, dallı zincirli aminoasit ve glukoz metabolizmasındaki birçok oksidasyon-redüksiyon reaksiyonuna katılmaktadır. Krebs döngüsünde adenozin trifosfat (ATP) oluşumu için gerekli oksidatif dekarboksilasyon için elzemdir (Eshak ve Arafa, 2018). Tahıllar, yağlı tohumlar ve organ etlerinde yüksek miktarda bulunan tiamin, glikoz metabolizmasında önemli rol oynayarak, beynin temel enerji kaynağını sağlar (Beyhan ve Taş, 2019). Tiaminden zengin besinler; tam tahıl ürünleri, et, kurubaklagillerler ve yağlı tohumlardır (Whitfield vd., 2018). Tahıl, biftek, yağlı tohumlar ve maya gibi birçok besinden elde edilebilmesine rağmen parlatılmış pirinç, öğütülmüş buğday unu, süt, sebze ve meyveler gibi bazı yaygın besin grupları tiamin açısından fakirdirler (Eshak ve Arafa, 2018). Diğer taraftan yüksek 1s1 ve $\mathrm{pH}$, tiamin üzerinde denatüre edici etki yaratmaktadır. Bu nedenle, pişirme, firınlama, pastörizasyon ve gidaların korunması, tiaminin bozulmasına neden olabilir (Eshak ve Arafa, 2018). Dünya çapındaki birçok popülasyon, kıtlık, düşük tiamin içeriğine sahip temel ürünlere güvenme veya tahıl öğütme, öğütülmüş pirincin yıkanması gibi gıda hazırlama uygulamaları nedeniyle klinik veya subklinik tiamin eksiklikleri riski altında olabilir (Whitfield vd., 2018). Tiaminin aynı zamanda çeşitli transmitterlerin sentezi için de gerekli olduğu ve eksikliğinde konfüzyon, mental değişiklikler, dengesizlikler ve hafıza kaybı görüldüğü bildirilmiştir (Beyhan ve Taş, 2019). Türkiye'ye Özgü Beslenme Rehberine göre 19-50 yaş erkek birey için tiamin gereksinimi 1,2 mg iken aynı yaş grubundaki kadınlar için bu rakam 1,1 mg olarak belirlenmiştir (TÜBER, 2015). Tiaminin fazla alımının herhangi bir yan etkisi bilinmemektedir ve tiamin için bir üst alım seviyesi belirlenmemiştir (Whitfield vd., 2018).

Çalışmamızda 100 gram haşlanmış makarna ve eriştede sindirim sonrası tiamin içeriği en yüksek ve düşük olan ürünler sirasiyla tam buğday unu makarnası $(105,2 \pm 5,0 \mu \mathrm{g} / 100 \mathrm{~g})$ ve glutensiz makarna $(11,8 \pm 0,5 \mu \mathrm{g} / 100 \mathrm{~g})$ olarak saptanmıştır. Saptanan ürünler TURKOMP'taki verilere kıyasla düşük bulunmuştur (TURKOMP, 2021). Çalışmamızdaki ürünlerin tiamin biyoerişilebilirliği \%80,0 46,1 ila $99,8 \pm 7,6$ arasında bulunmuştur. En düşük tiamin biyoerişilebilirliğinin yumurtalı eriştede olduğu saptanmıştır. En yüksek biyoerişilebilirliğin ise 1spanaklı makarnada olduğu gözlemlenmiştir. Ekmek çeşitlerindeki tiamin biyoerişilebilirliklerinin araştırıldı ğ makalede ise bu oranlar \% 45-73 arasında bulunmuştur. En yüksek biyoerişilebilirik tam buğday ununda saptanırken, en düşük oran 
ise yulaf ekmeğinde görülmüştür. Araştırmacı, düşük biyoerişilebilirliğin ürünlerin yüksek diyet lifinden kaynaklandığını belirtmiştir (Yaman, 2019). Akça ve arkadaşlarının yapmış olduğu çalışmada ise tahıl bazlı bebek mamalarındaki tiamin biyoerişilebilirliği incelemiş ve yazarlar farklı gastrik $\mathrm{pH}$ ortamlarında tiamin biyoerişilebilirliğinin etkilendiğini belirtmişlerdir, çalışmada en yüksek biyoerişilebilirlik $\mathrm{pH} 1,5$ ' da $\% 82 \pm 2$, $\mathrm{pH} 4$ 'te ise $\% 65 \pm 1$ olarak saptanmıştır (Akça, Sargın, Mızrak ve Yaman, 2019). Mevcut çalışmamızda ise tiaminin biyoerişilebilirlik oranı $\% 80,0 \pm 6,1$ ila $\% 99,8 \pm 7,6$ arasında bulunmuştur. $B_{1}$ vitamininin stabilitesi 1s1 işlemler ve pH'tan etkilenmektedir (Yaman, 2019). Bilindiği gibi, pişirme ile nişasta ve protein sindirilebilirliği artmaktadır (Barampama ve Simard, 1995). Isıl işlem sonucu nişastanın jelatinizasyonu ve proteinin denaturasyonuna bağlı olarak besinlerin sindirilmesi daha kolay olmaktadır (Tamura, Singh, Kaur ve Ogawa, 2016). B grubu vitaminler polipeptitlere ve polisasakkaritlere bağlı olarak besinlerde bulunabilir (Yaman vd, 2021). Bu çalışmada makarnaların pişirilmesi sonucu nişasta ve proteinlerin yapısının bozulmasına bağlı olarak tiaminin daha kolay gastrointestinal sistemde serbest hale geldiği ve in vitro biyoerişilebilirliğinin bu nedenle yüksek olduğu düşünülmektedir.

\section{Sonuç}

Ülkemizde de sık tüketilen besinlerden olan makarna ve erişte çeşitlerinde bulunan tiaminin biyoerişilebilirliğinin incelendiği çalışmamızda en yüksek biyoerişilebilirlik 1spanaklı makarnadan elde edilmiştir. Tüm veriler değerlendirildiğinde ise makarna ve erişte türlerindeki tiamin biyoerişilebilirlikleri göreceli yüksek olmakla birlikte tiamin içeriklerinin nispeten düşük olduğu göz ardı edilmemeli ve bireylerin beslenmelerinde tiamin içeriği yüksek olan tam tahıl ürünlerine yer vermeye özen gösterilmesi gerektiği düşünülmüştür.

\section{Teşekkür}

İstanbul Sabahattin Zaim Üniversitesine desteklerinden dolayı teşekkür ederim.

\section{Kaynakça}

Akça, S. N., Sargın, H. S., Mızrak, Ö. F., \& Yaman, M. (2019). Determination and assessment of the bioaccessibility of vitamins B1, B2, and B3 in commercially available cerealbased baby foods. Microchemical Journal, 150(March), 104192. https://doi.org/10.1016/j.microc.2019.104192.

Barampama, Z., \& Simard, R. E. (1995). Effects of soaking, cooking and fermentation on composition, in-vitro starch digestibility and nutritive value of common beans. Plant Foods for Human Nutrition, 48(4), 349-365.

Beyhan, Y., \& Taş, V. (2019). Mental Sağlık ve Beslenme. Zeugma Health Science, 1(1), 30-35.

Duda, A., Adamczak, J., Chelminska, P., Juszkiewicz, J., \& Kowalczewski, P. (2019). Quality and nutritional/textural properties of durum wheat pasta enriched with cricket powder. Foods, 8(2), 1-10. https://doi.org/10.3390/foods8020046.

Eshak, E. S., \& Arafa, A. E. (2018). Thiamine deficiency and cardiovascular disorders. Nutrition, Metabolism and Cardiovascular Diseases, 28(10), 965-972. https://doi.org/10.1016/j.numecd.2018.06.013.
Kennedy, D. O. (2016). B vitamins and the brain: Mechanisms, dose and efficacy-A review. Nutrients, 8(2). https://doi.org/10.3390/nu8020068.

Lee, S. J., Lee, S. Y., Chung, M. S., \& Hur, S. J. (2016). Development of novel in vitro human digestion systems for screening the bioavailability and digestibility of foods. Journal of Functional Foods, 22, 113-121. https://doi.org/10.1016/j.jff.2016.01.005.

Leporati, A., Catellani, D., Suman, M., Andreoli, R., Manini, P., \& Niessen, W. M. A. (2005). Application of a liquid chromatography tandem mass spectrometry method to the analysis of water-soluble vitamins in Italian pasta. Analytica Chimica Acta, 531(1), 87-95. https://doi.org/10.1016/j.aca.2004.10.006.

López-Gámez, G., Elez-Martínez, P., Martín-Belloso, O., \& Soliva-Fortuny, R. (2021). Recent advances toward the application of non-thermal technologies in food processing: An insight on the bioaccessibility of health-related constituents in plant-based products. Foods, 10(7). https://doi.org/10.3390/foods10071538.

Melini, V., Melini, F., \& Acquistucci, R. (2020). Phenolic compounds and bioaccessibility thereof in functional pasta. Antioxidants, 9(4), 1-30. https://doi.org/10.3390/antiox9040343.

Muslu, A., Gider, S.,Dereli, FB.,Yüksel, F. (2021). Üniversite Öğrencilerinin Makarna Tüketim Alışkanlıklarını ve Bunu Etkileyen Faktörlerin İncelenmesi. 10(2), 273-281.

Ndaw, S., Bergaentzlé, M., Aoudé-Werner, D., \& Hasselmann, C. (2000). Extraction procedures for the liquid chromatographic determination of thiamin, riboflavin and vitamin B6 in foodstuffs. Food Chemistry, 71(1), 129-138. https://doi.org/10.1016/S0308-8146(00)00135-7.

Schellack, G., Harirari, P., \& Schellack, N. (2016). B-complex vitamin deficiency and supplementation. $S A$ Pharmaceutical Journal, 83(4), 14-19.

Tamura, M., Singh, J., Kaur, L., \& Ogawa, Y. (2016). Impact of the degree of cooking on starch digestibility of rice-An in vitro study. Food Chemistry, 191, 98-104.

TURKOMP. (2021). Türk besin kompozisyonu veri taban1. http://www.turkomp.gov.tr/food-132. Erişim Tarihi: 30.10.2021.

TÜBER 2015. (2016). T.C. Sağlık Bakanlığı Yayın No: 1031, Ankara. Erişim Tarihi: 30.10.2021.

Whitfield, K. C., Bourassa, M. W., Adamolekun, B., Bergeron, G., Bettendorff, L., Brown, K. H., ... Combs, G. F. (2018). Thiamine deficiency disorders: diagnosis, prevalence, and a roadmap for global control programs. Annals of the New York Academy of Sciences, 1430, 3-43. https://doi.org/10.1111/nyas.13919.

Yaman, M. (2019). Farklı Ekmek Çeşitlerinde Doğal Olarak Bulunan Vitamin B1, B2 ve B6'nın İn vitro Biyoerişebilirliğinin İncelenmesi. European Journal of Science and Technology, (16), 758-764. https://doi.org/10.31590/ejosat.593444.

Yaman, M., Çatak, J., Uğur, H., Gürbüz, M., Belli, İ., Tanyıldız, S. N., ... Yaldiz, M. C. (2021). The bioaccessibility of water-soluble vitamins: A review. Trends in Food Science and Technology, 109(April 2020), 552-563. https://doi.org/10.1016/j.tifs.2021.01.056. 